\title{
Using Technology as a Novel Method to Develop Students' Clinical Reasoning Skills Through Virtual Collaborative Learning in Scriptwriting
}

\author{
Anecita Gigi LIM ${ }^{\mathrm{a}, 1}$ and Michelle HONEY ${ }^{\mathrm{a}}$ \\ ${ }^{a}$ School of Nursing University of Auckland, Auckland, New Zealand
}

\begin{abstract}
One of the most important skills students need to learn in applying pharmacotherapeutics is clinical reasoning. This study aimed to evaluate the impact of virtual collaboration in scriptwriting as a teaching approach to develop clinical reasoning skills. Data was from student feedback $(\mathrm{n}=102)$. Discussing conceptual questions in a collaborative learning environment with peers proved to support the development of clinical reasoning skills as the activity increased interactivity, improved understanding and retention. Findings show that the development of clinical reasoning skills were enhanced with the use of scriptwriting as a virtual collaborative activity.
\end{abstract}

Keywords. Nursing education, virtual collaboration, educational use of technology

\section{Introduction}

Nurses need to be able to work together effectively and education can provide opportunities to develop collaborative skills alongside providing content specific knowledge. Technology can support virtual collaborative learning and this paper provides an example of this through scriptwriting in one postgraduate nursing course. Technology was found to enable virtual collaboration with students using an innovative teaching approach involving scriptwriting in groups.

Collaborative learning is based on social constructivism; that knowledge is socially situated and knowledge is constructed in interaction with others [1]. Unlike individual learning, people engaged in collaborative learning are able to capitalize on one another's resources and skills, which draws on Vygotsky's theory of working within the zone of proximal development [2]. Collaborative learning as an approach to scriptwriting provides opportunities and support for the development of clinical reasoning skills in pharmacotherapeutics and enhances student's existing skills in interprofessional communication.

Scriptwriting, as a teaching approach, is an innovative method to promote collaborative learning, interaction and critical thinking between students [3]. One of the most important skills that students need to learn in pharmacotherapeutics is clinical

${ }^{1}$ Corresponding Author, Dr Anecita Gigi Lim, School of Nursing, University of Auckland, Private Bag 92019, Victoria Street West, Auckland 1142, New Zealand; E-mail: g.lim@auckland.ac.nz. 
reasoning as this underpins safe and effective prescribing. The importance of clinical reasoning in building pharmacotherapeutic competence is critical [4]. Discussing conceptual questions in a collaborative learning environment with peers, such as through scriptwriting, is likely to motivate the development of clinical reasoning skills $[3,5]$.

Higgs and Jones [6] describe clinical reasoning as a context driven and context dependent way of thinking and decision-making in professional practice that guides action. Health care professionals wishing to use their judgment and decision-making skills face a key challenge, as in most situations, each decision they make requires them to think about an uncertain future; indeed, health care decisions are usually made under conditions of uncertainty. This applies to pharmacotherapeutics, where the prescriber weighs up risk versus benefit when deciding a course of action.

Kolb was highly influential in describing how learning takes place and helping understanding of the learning process [7]. His "learning cycle", uses reflective learning as a learning approach and the idea of learning as experiential (learning by doing). In the education and teaching of health professionals, much of the learning is necessarily experiential, there is a lot of 'learning by doing' as well as 'learning by observation' c[8]. Kolb suggests that ideas are not fixed, but are formed and modified through experience and by past experience [7]. These concepts underpin prevailing ideas in medical and other professional education and training such as the reflective practitioner and becoming an expert. Providing opportunities for learners to develop these skills is essential.

The technology used to support computer learning is often best using multi modal approaches [9]. The term computer-supported collaborative learning was used as early as 1989 by O'Malley and Scanlon [9] and this has emerged as a dynamic, interdisciplinary, and international field of research that focused on how technology can facilitate the sharing and creation of knowledge and expertise through peer interaction and group learning processes. It includes a range of situations in which interactions take place among students using computer networks to enhance the learning environment. It includes the use of technology to support asynchronous and synchronous communication between students on-campus as well as students who are geographically distributed. The overall aim is to provide an environment that supports collaboration between students to enhance their learning process $[3,10]$.

\section{Methods}

The aim of this project was to: evaluate the impact of scriptwriting as a teaching approach in developing clinical reasoning skills and for developing collaborative practice when mediated by technology. The context was a postgraduate nursing course on clinical pharmacotherapeutics. The purpose of using scriptwriting was to get students to write a script that demonstrated clinical reasoning using virtual collaborative group learning. Scriptwriting is used in this course to help students develop knowledge and skills in clinical reasoning in prescribing. It is used as a group activity designed to enhance students' problem-solving skills and their ability to articulate their clinical reasoning and decision making. The students are all postgraduate students who have been working as nurses for at least three years. The nurses are working across the country, hence the need for a virtual collaborative approach.

The technology used in this context to support collaborative learning was a learning management system called Canvas where students were allocated into groups and worked together on a case presentation, with the aim of producing a script to capture the 
creation of knowledge related to the pharmacotherapeutic approaches that were identified. Participants were enrolled students who completed the course in 2019. Students were asked to reflect on their individual contribution to the scriptwriting task and the development of their understanding of the therapeutic reasoning process. Using a reflective approach, students were ask to provide insights into their personal engagement, contribution to the task, and their organization skills. Thematic analysis was used to identify core categories and themes to elicit respondents' perceptions and reflections of their learning in a virtual collaborative environment and in terms of their development of clinical reasoning skills in pharmacotherapeutics.

\section{Results}

Thematic analysis identified two important aspects of learning: Collaborative learning and enhanced clinical reasoning skills. These will now be described.

\subsection{Collaborative Learning}

Enhanced skills in collaborative learning was reported by participants. The use of technology enhanced the development of their skills in communication, such as good communication skills, as one participant reported: "...we often had a few disagreements which were settled by posting large discussions that encompassed everybody's opinion". In addition, the majority felt that the collaborative learning using technology enhanced their skills in communicating. For example, one participant stated, "I had to think about how to collaborate with pharmacists and doctors to ask their opinion of ways to manage Mary".

\subsection{Enhanced Clinical Reasoning Skills}

Overall the majority were of the view that working together collaboratively provided the opportunity to develop their critical thinking and clinical reasoning skills as one participant describes: "...many hours of reading and consolidation went into ensuring the script contained evidence of consideration and clinical reasoning pertaining to potential medication interactions, side effects, and benefits". The participants also highlighted how the computer supported their learning because as they wrote the script, this provided an opportunity to better understand the prescribing process and the issues that they were likely to encounter as prescribers who considered the safety and efficacy of treatment. As one participant stated, "This assignment provided me great insight into the complexity of the prescribing process and I believe that I now have a more in-depth understanding of this process".

\section{Discussion}

The effectiveness of virtual collaborative learning to promote skills in clinical reasoning was evident in the students' self-reflection narratives which aligns with the findings by Cavdar and Doe [11]. Students in this study were able to clearly articulate how working with a group to solve a problem enhanced their problem-solving skills, inspired critical 
thinking, helped develop self-management skills, fostered the development of communication skills and relationships, again supported by literature [1].

Globally, collaborative learning mediated with technology is well recognised with innovative examples including using second life [12] and via social media [13]. This study reports on scriptwriting, so the learning activity of writing a script rather than the use of technology is novel. This study demonstrated that using the learning management system that students already know takes the focus from the technology and places it on the learning activity, which is supported by others who found using software that students are familiar with is helpful [13].

This study shows that a simulation-based activity like scriptwriting supports knowledge and skills related to pharmacotherapeutics to be developed as well as clinical reasoning, communication and knowledge consolidation. The use of technology allowed dispersed students to mutually engage and participate in a coordinated effort to solve a problem, so through interaction, cooperation, and collaboration, learning occurs. Similar benefits of collaborative learning a re highlighted by Laaland Ghodsi [1].

It was anticipated this teaching approach would positively impact students' clinical reasoning skill development including the ability to self-evaluate and interact effectively, however this study only involved nurses, which is a limitation. An a rea for further research is to extend this work to other health professionals and therefore consider interprofessional learning.

\section{Conclusion}

Overall this study has shown that students do benefit from a technology based collaborative learning approach when engaging in the learning of pharmacotherapeutic principles. Not only did this approach consolidate students' knowledge of pharmacotherapeutics, skills in communication and clinical reasoning were also developed. Furthermore, by using the learning management system that students were familiar with, the focus remained on the learning activity of scriptwriting, and not on the technology.

\section{References}

[1] Laal M, Ghodsi SM. Benefits of collaborative learning. Social and Behavioral Sciences 31, (2012), 486490.

[2] Tudge J. Vygotsky, the zone of proximal development, and peer collaboration: Implications for the classroom. In: Moll L, ed. Vygotsky and Education: Instructional implications and applications of sociohistorical psychology, Cambridge University Press, Cambridge, United Kingdom, 1990.

[3] Cavdar G, Doe S. Learning through writing: Teaching critical thinking skills in writing assignments. Political Science and Politics 45, (2012), 298-306.

[4] Fonteyn ME, Ritter BJ. Clinical reasoning in nursing. In: Higgs J, Jones MA, Loftus S, Christensen N, eds. Clinical reasoning in the health professions. 3rd ed, Elsevier, Amstersam, 2008, 235-244.

[5] Öz M, Kabataş Memiş E. Effect of multi modal representations on the critical thinking skills of the fifth grade students. International Journal of Progressive Education 14, (2018), 209-227.

[6] Higgs J, Jones MA. Clinical decision making and multiple problems spaces. In: Higgs J, Jones MA, Loftus S, Christensen N, eds. Clinical reasoning in the health professions, 2008, 3-17.

[7] Kolb D. Learning style inventory: Technical manual. McBer, Boston, 1976.

[8] McLeod SA. Kolb's learning styles and experiential learning cycle. 2017, https:/www.simplypsychology.org/learning-kolb.html 
[9] Resta P. Technology in support of collaborative learning. Education Psychology Review 19, (2007), 6583.

[10] Schön DA. From technical rationality to reflection-in-action. In: Downie J, Elstein A, eds. Professional judgement: A reader in clinical decision making, Cambridge University Press, Cambridge, England, 1988, 60-77.

[11] Cavdar G, Doe S. Learning through writing: Teaching critical thinking skills in writing assignments. Political Science and Politics 45, (2012), 298-306.

[12] Veltman M, Connor K, Honey M, Diener S, Bodily D. Collaborative practice through simulations in a multiuser virtual environment. CIN: Computers, Informatics, Nursing 30, (2012), 63-67.

[13] Procter PM, Brixey JJ, Todhunter F, Honey ML. Social media providing an international virtual elective experience for student nurses. Informatics 4, (2017), 1-8. 